\title{
Use of simple analgesics in rheumatoid arthritis
}

\author{
T GIBSON AND B CLARK \\ From the Department of Rheumatology, Guy's Hospital, London SE1 9RT
}

SUMMARY The usefulness of anti-inflammatory drugs in rheumatoid arthritis (RA) is beyond dispute. The role of simple analgesics is less clear and has been disputed. A survey of 21 rheumatologists indicated that a majority sometimes supplemented anti-inflammatory treatment of RA with simple analgesics. A random sample of $120 \mathrm{RA}$ patients treated by the same doctors revealed that $47 \%$ ranked pain relief as the most desirable objective of their treatment and $54 \%$ were taking analgesics regularly. Of those receiving analgesics as well as non-steroidal anti-inflammatory drugs $48 \%$ considered the former to be the more effective preparations. Almost half the patients on analgesics were taking drugs without the knowledge of the rheumatologists, who may have underestimated their patients' desire for pain relief.

$\bar{K}$ ey words: pain relief, patient preference, prescribing practice.

Logically a disease with the inflammatory features of rheumatoid arthritis can be best treated with agents which exert an anti-inflammatory effect. The usefulness of analgesics devoid of anti-inflammatory properties is unclear, even though they are commonly prescribed or otherwise obtained by patients. ${ }^{1}$

The present study was designed to answer three principal questions: What benefits do patients with RA most hope to obtain from the drugs they receive for their arthritis? What role do hospital doctors assign to simple analgesics in the management of RA? Are these views shared by their patients?

\section{Patients and methods}

The survey was conducted at four London teaching hospitals. Nine consultant rheumatologists and 12 registrars completed a questionnaire which asked whether the respondents considered that simple analgesics were worth prescribing in RA and, if so, what preparations they prescribed and how often. A random sample of rheumatoid patients treated by the same clinicians were interviewed. They were asked to rank the following objectives of treatment in order of importance: $(a)$ relief of stiffness, $(b)$ prevention of deformities, $(c)$ increased physical activity, $(d)$ relief of pain, $(e)$ reduction of swelling. The interviewer then compiled a list of patients'

Accepted for publication 7 June 1984.

Correspondence to $\mathrm{Dr} \mathrm{T}$ Gibson. treatments, and asked about the need for regular 'pain-killers' taken with or without the hospital's knowledge. Each patient was requested to rank the treatments in order of effectiveness and to indicate where any listed analgesic was initially obtained. Hospital notes were reviewed to determine whether all the drugs were documented. Each patient's joint tenderness was then scored. ${ }^{2}$ Results were analysed by Student's $t$ test and the $\chi^{2}$ test.

\section{Results}

Eighteen (85\%) rheumatologists thought that analgesics were worth prescribing but three (one consultant; two registrars) did not. A minority (four registrars) prescribed analgesics often, the remainder doing so sometimes or rarely. No rheumatologist failed to prescribe these drugs. Paracetamol and Distalgesic (paracetamol-dextropropoxyphene) were the most popular choices. The range of analgesics which rheumatologists were prepared to prescribe was confined to six drugs. No hospital was identifiable by a common response to the questions.

There were 120 patients in the survey, and all identified one treatment objective which they considered the most important. Some could not distinguish between objectives which they considered of less importance (Table 1$)$. Almost half $(47 \%)$ gave first priority to pain relief, but reduction of stiffness $(10 \%)$ and swelling $(2 \%)$ were not viewed as highly desirable benefits. This distribution was significantly 
Table 1 Objectives of drug treatment ranked in order of importance by patients.

\begin{tabular}{|c|c|c|c|c|c|}
\hline Rank order & $I$ & 2 & 3 & 4 & 5 \\
\hline Relief of stiffness & $12(10 \%)$ & $24(20 \%)$ & $39(30 \%)$ & $32(26 \%)$ & $13(13 \%)$ \\
\hline Prevention of deformities & $24(20 \%)$ & $28(23 \%)$ & $32(25 \%)$ & $21(17 \%)$ & $13(13 \%)$ \\
\hline Increased physical activity & $25(21 \%)$ & $27(22 \%)$ & $18(14 \%)$ & $28(23 \%)$ & $19(19 \%)$ \\
\hline Relief of pain & $57(47 \%)$ & $33(27 \%)$ & $20(15 \%)$ & $8(7 \%)$ & $3(4 \%)$ \\
\hline Reduction of joint swelling & $2(2 \%)$ & $9(8 \%)$ & $21(16 \%)$ & $33(27 \%)$ & $50(51 \%)$ \\
\hline Totals & 120 & 121 & 130 & 122 & 98 \\
\hline
\end{tabular}

different from the expected $\left(\chi^{2}=71 ; \mathrm{p}<0.0005\right)$. Those who gave first ranking to pain relief did not have greater joint tenderness nor could they be otherwise distinguished (Table 2).

Simple analgesics were taken regularly by 65 $(54 \%)$ patients. The range of drugs is listed in Table 3 . In $28(43 \%)$ of these cases the analgesics were not documented in the hospital records. Patients claimed that a hospital rheumatologist first prescribed the listed analgesic in $32(49 \%)$ instances and the general practitioner in $24(37 \%)$. Only nine $(14 \%)$ admitted buying analgesics. Seven patients on analgesics were receiving no anti-inflammatory drugs. Of those receiving both, $28(48 \%)$ considered that the analgesics were more effective, $20(35 \%)$ thought that they were less effective, and $10(17 \%)$ viewed them as equally helpful.

Table 2 Mean $( \pm S D)$ of clinical characteristics of patients grouped according to their first choice of treatment objective

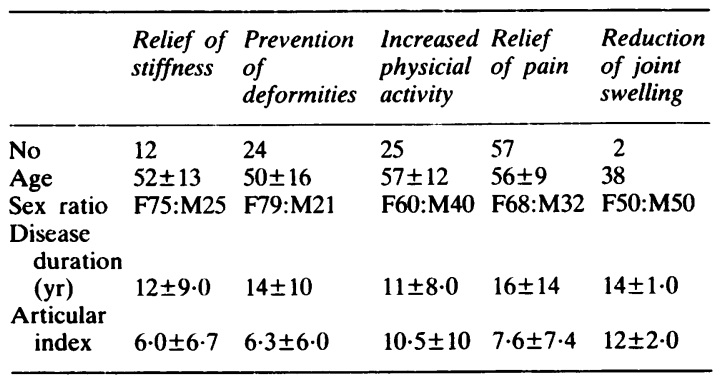

Table 3 Range of simple analgesics being taken by 65 of 120 patients in the survey

\begin{tabular}{|c|c|c|c|}
\hline $\begin{array}{l}\text { Distalgesic: } \\
\text { Paracetamol: }\end{array}$ & $\begin{array}{l}35 \\
13\end{array}$ & $\begin{array}{l}\text { Dihydrocodeine: } \\
\text { Low dose } \\
\text { salicylates: }\end{array}$ & 3 \\
\hline $\begin{array}{l}\text { Other paracetamol } \\
\text { combinations: } \\
\text { with aspirin: } \\
\text { with codeine: }\end{array}$ & $\begin{array}{l}3 \\
3\end{array}$ & $\begin{array}{l}\text { Pentazocine: } \\
\text { Nefopam: }\end{array}$ & $\begin{array}{l}3 \\
1\end{array}$ \\
\hline
\end{tabular}

\section{Discussion}

It has been suggested that simple analgesics arêu ineffective ${ }^{3}$ in RA, and in some accounts of treato ment they are not mentioned. ${ }^{4}$ On the other hand it has been argued that the addition of centrally acting analgesics to the peripherally acting antis inflammatory drugs is rational ${ }^{5}$ and that if patient\$్ are not given them they will obtain them. ${ }^{6}$

Most of the rheumatologists in our survey prece scribed analgesics sometimes, and this was coner firmed by the patients' accounts of initial analgesie prescribing. The analgesics favoured by the rheumao tologists matched those taken by the patients? although Distalgesic was taken more frequently that might have been anticipated from the rheumatolo gists' replies.

One disturbing feature of our study was the frequent use of analgesics without the knowledge of the rheumatologists. This may have reflected failures of communication, but it is also possible. that the patients' aims and expectations differed fronis those of the doctors. The survey of therapeutio objectives as perceived by the patients left no doub $B$. that pain relief was by far the most desired end point, and half those taking both anti-inflammatory and simple analgesics thought the latter mores effective. However, one cannot conclude that simple analgesics are more or less effective that anti-inflammatory drugs from such data. Pain relief is a predictable benefit of anti-inflammatory treato ment, and in one study analgesics were found to bes less effective than anti-inflammatory doses of salicyis lates in RA. ${ }^{7}$ Other studies of analgesics given along or as supplements to anti-inflammatory drugs have produced conflicting results. -10 $^{-10}$

Our survey shows that a substantial number o⿱ patients with RA want pain relief above all else. The desire for adequate analgesia and the demand fo 5 simple analgesics may have been underestimated b. the rheumatologists. There is a need for furthe evaluation of both new and established simple analgesics in this disorder. 
We are grateful to the rheumatology consultants and registrars of Guy's. Lewisham, King's College, and St. Thomas's Hospitals for their help and cooperation.

\section{References}

1 Lee P. Ahola S. Grennan D. Brooks P. Buchanan W W. Observations on drug prescribing in rheumatoid arthritis. $\mathrm{Br}$ Med J 1974; i: 424-6.

2 Ritchie D. Boyle J, Mclnnes J, et al. Clinical studies with an articular index for the assessment of joint tenderness in patients with rheumatoid arthritis. $Q J$ Med 1968: 37: 393-406.

3 Nuki G. Non-steroidal analgesic and anti-inflammatory agents. $\mathrm{Br}$ Med J 1983: 287: 39-43.

4 Constable T. Crockson R. Crockson A. McConkey B. Drug treatment in rheumatoid arthritis. Lancet 1975; i: 1176-80.
5 Kantor T. Analgesics for arthritis. In: Huskisson E, ed. Anti-rheumatic drugs, II. Clin Rheum Dis 1980: 6: 525-31.

6 Huskisson E. Simple analgesics for arthritis. Br Med J 1974; iv: 196-200.

7 Fremont Smith P, Bayles T. Salicylate therapy in rheumatoid arthritis. JAMA 1965: 192: 103-6.

8 Hardin J G, Kirk K A. Comparative effectiveness of 5 analgesics for the pain of rheumatoid arthritis. J Rheumatol 1979; 6: 405-42.

9 Nuki G, Downie W, Dick W C, et al. Clinical trials of pentazocine in rheumatoid arthritis. Observations on the value of potent analgesics and placebos. Ann Rheum Dis 1973; 32: 436-43.

10 Brooks P M. Dougan M A, Mugford S. Meffin E. Comparative effectiveness of 5 analgesics in patients with rheumatoid arthritis and osteoarthritis. $J$ Rheumatol 1982; 9: 723-6. 